\title{
PARDO BAZÁN, POLEMISTA ILUSTRADA. LA REALIDAD DE LA FICCIÓN EN “EL INDULTO" Y “VIERNES SANTO"
}

\author{
PARDO BAZÁN, ILLUSTRATED POLEMICIST. THE REALITY OF FICTION IN “EL \\ INDULTO" AND “VIERNES SANTO”
}

\section{María Elena Ojea Fernández}

\section{Resumen:}

La preocupación de Pardo Bazán por los problemas sociales y políticos de España, hizo que reflexionara con osadía acerca de asuntos que inundan sus artículos y obras de ficción, tales como la situación femenina o la corrupción política. Hemos escogido dos cuentos, El indulto y Viernes santo para señalar hasta qué punto la condesa fue una intelectual comprometida con su tiempo y cómo no temió enfrentarse a una sociedad que negaba a las mujeres el derecho a disentir abiertamente.

\section{Palabras claves:}

situación femenina, corrupción, compromiso, osadía.

\section{Abstract:}

Emilia Pardo Bazán's concern about social and political problems of Spain led her to deal with boldness and reflection of two important issues -female situation and political corruption- that fill up many of her articles and works of fiction. We have chosen two short stories, El indulto and Viernes santo, to indicate the extent to which the Countess was a committed intellectual with her time and how she was not afraid to face a society that denied women the right to speak out publicly.

\section{KeY WORD:}

female situation, political corruption, commitment, boldness. 


\section{Introducción}

Emilia Pardo Bazán fue un ejemplo sorprendente de mujer intelectual. Difundió su saber en innumerables relatos, artículos y conferencias, trató los temas más candentes del momento y permaneció durante años en el primer plano de la vida social y cultural de su país. A pesar de ser una escritora tradicionalista, compaginó con acierto su ideología con la exploración del mundo social, en especial, con la defensa del derecho de la mujer al conocimiento y a la participación activa en la sociedad. Hemos escogido dos relatos breves (El indulto y Viernes santo), que acaso revelan algunas de las grandes preocupaciones de la escritora gallega: la difícil situación de la mujer española y la corrupción política.

En la segunda mitad del siglo XIX, la emancipación de la mujer fue tema de gran controversia. Nietzsche decía que el mero hecho de que una mujer quisiera ser independiente era el peor desarrollo del afeamiento en Europa: "se va volviendo cada vez más histérica y más incapaz de cumplir su función primaria y única: la de dar a luz hijos robustos" (Ciplijauskaité, 1984: 46). Si el pensador alemán personifica la hostilidad del mundo patriarcal hacia las mujeres independientes, la condesa de Pardo Bazán encarna a esa mujer tan denostada que se niega a aceptar los roles designados por la tradición. Tanto en su vida privada como en su vida profesional, la escritora fue abanderada de la libertad de pensamiento. Bajo esta perspectiva, en los relatos breves El indulto y Viernes santo, descubrimos a la ciudadana inconformista, siempre vigilante y siempre crítica ante los excesos del poder político.

\section{El indulto}

El desamparo de las mujeres maltratadas es el argumento del famoso cuento $E$ l indulto. En este relato se narra la historia de Antonia, una humilde asistenta que vive dominada por el terror a que su marido -en prisión por el asesinato de la madre de ella® regrese algún día. El miedo al perdón real la consume lentamente: “La hipótesis de la muerte natural no la asustaba, pero la espantaba solamente que volvía su marido" (Pardo Bazán, 1990: 122, I). Doña Emilia construye un relato admirable que retrata con suma maestría la psicología de una mujer maltratada. La legislación penal, la benevolencia de la justicia para con el hombre, el divorcio o la denuncia de las agresiones a mujeres quedan patentes en un relato que presenta claramente las inquietudes feministas de la condesa, sin duda su faceta más progresista.

La construcción del personaje de Antonia es un acierto narrativo. Doña Emilia dibuja un personaje atormentado que pasa sin dilación del terror a la felicidad, como ocurre cuando da por sentado que su esposo ha muerto:
¡Muerto el criminal, en víspera del indulto, antes de cumplir el plazo de su castigo Antonia la asistenta alzó la cabeza y por primera vez se tiñeron sus mejillas de un sano color y se abrió la fuente de sus lágrimas. Lloraba de gozo, y nadie de los que la miraban se escandalizó. Ella era la indultada; su alegría, justa. Las lágrimas se agolpaban en sus lagrimales, dilatándole el corazón. (Pardo Bazán, 1990: 125, I)

Pero para su desgracia la realidad es otra. El inesperado retorno del parricida: “Era él Antonia, inmóvil, clavada al suelo, no le veía ya, aunque la siniestra imagen se reflejaba en sus dilatadas pupilas. Su cuerpo yerto sufría una parálisis momentánea" (Pardo Bazán, 1990: 125, I), ahoga el grito de socorro de la pobre asistenta que lentamente se deja morir.

Y el niño fue quien, gritando desesperadamente llamó al amanecer a las vecinas que encontraron a Antonia en la cama, extendida, como muerta. El médico vino aprisa, y declaró que vivía y la sangró, y no logró sacarle gota de sangre. Falleció a las veinticuatro horas, de muerte natural, pues no tenía lesión alguna. (Pardo Bazán, 1990: 127, I)

La historia muestra cómo el terror al maltrato físico acaba por enajenar a la desdichada que muere sin que nadie pueda evitarlo. Deja al descubierto el desinterés de la justicia hacia la violencia doméstica y presenta a las mujeres como seres de segunda categoría en cuyo bienestar nadie repara. Únicamente la solidaridad de las vecinas consuela a Antonia: “¿Qué leyes, divino Señor de los cielos! ¡Así los bribones que las hacen las aguantaran! ๑clamaba indignado el coro. ¿Y no habrá algún remedio, mujer, no habrá algún remedio?" (Pardo Bazán, 1990: 123, I). El cuento es una queja en toda regla: las mujeres existen y tienen humanidad. La mirada de P.B. es de compromiso y denuncia de una situación social y jurídica injusta. También de piedad ante el final de Antonia sentimiento ausente en la sociedad patriarcal.

El relato gira alrededor de tres puntos clave. Uno, el desamparo legal de la mujer que puede ser asesinada sin que nadie pague por ello. No olvidemos que una esposa debe sumisión a su marido. El segundo, una palabra impensable en la sociedad católica y patriarcal el divorcio: "Dicen que nos podemos separar... después de una cosa que llaman divorcio" (Pardo Bazán, 1990: 123, I). Claro está que sería más bien una especie de separación de cuerpos (Arnaud-Duc, 1993: 123), ya que el divorcio tal y como lo entendemos no se contemplaba en España. En tercer lugar, la solidaridad femenina:

Cuando nació el hijo de Antonia, ésta no pudo criarlo, tal era su debilidad y demacración y la frecuencia de las congojas que desde el crimen la aquejaban. Y como no le permitía el estado de su bolsillo pagar ama, las mujeres del barrio que tenían niños de pecho dieron de mamar por turno a la criatura que creció enclenque, resistiéndose de todas las angustias de su madre. (Pardo Bazán, 1990: $122,1)$ 
Las vecinas se solidarizan con Antonia porque en el sufrimiento de la infeliz ven todas el suyo propio. La condesa interpreta que sólo con la unión las mujeres alcanzarían la estima social que les pertenece.

Se armó una especie de motín. Había mujeres determinadas a hacer, decían ellas, una exposición al mismísimo rey, pidiendo contra indulto. Y, por turno, dormían en casa de la asistenta, para que la pobre mujer pudiera conciliar el sueño. Afortunadamente, el tercer día llegó la noticia de que el indulto era temporal, y al presidiario aún le quedaban algunos años de arrastrar el grillete. (Pardo Bazán, 1990: 124, I)

A pesar de los privilegios de clase, la condesa padeció los impedimentos de la sociedad patriarcal. Su matrimonio con don José Quiroga se deterioró muy pronto. Se apunta como posible motivo el hecho de que la vocación literaria de nuestra autora despertara los celos del marido. Es muy probable que las contrariedades matrimoniales sacaran a la luz su incipiente feminismo y el deseo de no disimular su talento. Su elevada estatura intelectual era inalcanzable para el esposo y doña Emilia contemplaría con estupor la altura inferior del hombre que por ley tiene derecho a imponerle su voluntad.

La obra literaria de Pardo Bazán nos ofrece la visión de una pensadora que se rebeló contra una sociedad que condenaba a la mujer a la sujeción. El destino de Antonia pasa por obedecer a su marido aunque sea un asesino. La condesa interpreta el triste destino de la asistenta como consecuencia de la discriminación social y económica con que el orden imperante castiga a las mujeres. Doña Emilia fue muy sensible a la humillación y siempre acudió en ayuda de las mujeres vejadas, aunque se tratara de personajes de ficción. Véase a este respecto la mordaz crítica a Tristana de Pérez Galdós. Pardo pensaba que únicamente con la independencia económica las féminas lograrían rescatar su conciencia, de ahí su indignación cuando Galdós mutila a la joven que anhela emanciparse. Sin embargo, el problema de la liberación femenina es más complejo, pues debemos tener en cuenta otros aspectos como la subjetividad. Antonia es oprimida por un marido que jura matarla y por una sociedad cuyos efectos nocivos la condenan a la obediencia. Al final, su atormentada subjetividad la vence y la única liberación que encuentra es la muerte. El fallecimiento de Antonia es símbolo del sufrimiento femenino atrapado en las arteras redes del matrimonio tradicional. El relato -una ficción realista que novela un hecho verídico- (González Arias, 1997: 161) juega tal vez sin pretenderlo con el inconsciente de la protagonista. La relación entre inconsciente femenino, subjetividad y sumisión se hace tan necesario como el estudio de las condiciones socio-económicas (Kirkpatrick, 1990: 160)

Doña Emilia fue una agitadora de conciencias que transformó el mundo femenino en sujeto de un discurso propio. La violencia física contra la mujer, el llamado mujericidio fue denunciado por la escritora que culpaba a la desigualdad jurídica de las agresiones impunes que sufrían las féminas, en especial las de clase baja. Sin embargo, el interés de nuestra autora por la violencia de género sería más una iniciativa personal que una empresa colectiva (Peñas Ruiz, 2008), pues doña Emilia no puede adherirse a ninguna corriente feminista organizada.

El cuento de El indulto expresa dos preocupaciones que la condesa tocará en sus artículos e incluso en sus obras de ficción. Por un lado, los crímenes domésticos, no ausentes de las primeras páginas de los periódicos: "Siguen a la orden del día los asesinatos de mujeres. Mató a su cónyuge, con certeros tiros"-se lamentaba la condesa(López Silva, 2013). Y prosigue:

No se puede decir que fuese traición la que cometió este individuo; no se le debe acusar de alevosía; él anunció, con la anticipación debida, lo que iba a suceder, él en tiempo. "Que la mato". Peor para la chica, y para la autoridad, si no lo evitaron, si le dejaron que cumpliese el fino gusto. (López Silva, 2013)

Y es que a través de sus relatos, Pardo ataca a los poderes públicos por su indiferencia su apatía y su ineptitud ante la violencia de género. Los artículos recogidos en $L a$ Ilustración Artística y en el libro De siglo a siglo dan fe de esa inquietud. No debemos olvidar que P.B. fue muy susceptible con la desigualdad jurídica de la mujer. Y es en el plano social donde Pardo describe con más claridad la fragilidad femenina. La escritora vincula las carencias jurídicas con la necesidad de una auténtica desfeudalización femenina (González Martínez, 1988: 21). La consecuencia de ese proceso sería la reivindicación del acceso de la mujer a una cierta individualidad, que consiste en que cada mujer además de disfrutar de la igualdad ante la ley, realice cambios internos. Era en definitiva una doble reivindicación: libertad social y libertad de ser (González Martínez, 1988: 22). La mujer carece de ideas propias, no tiene más que las de la sociedad que la esclaviza. Antonia no está en condiciones de sublevarse contra una sociedad que ni la apoya ni la protege, que no le abre ninguna vía y que la mantiene encadenada a su marido. La asistenta es, pues, fiel reflejo de un desequilibrio humillante. Aunque doña Emilia fue muy combativa en pro de los derechos civiles, quizá pasó por alto el tema de la subjetividad femenina. Pasividad, obediencia, humildad, paciencia eran cualidades que la tradición atribuía a la perfecta casada y que despertaban en el varón el deseo de redención. Antonia no fallece por transgredirlas sino más bien por no poder cumplirlas. Recordemos que acata las órdenes del marido con "la docilidad fatalista de la esclava" (Pardo Bazán, 1990: 127, I). La asistenta no muere por resistencia agresiva a las normas patriarcales; su drama es su incapacidad física y psicológica para cumplir los preceptos que la sociedad le impone.

3. Viernes santo 
La sociedad gallega de la Restauración ocupa un lugar destacado en la producción literaria de Pardo Bazán. Dentro del entramado de personajes destaca por mérito propio la omnipresente figura del cacique. En el relato de referencia, doña Emilia deja un testimonio clarificador y una lúcida comprensión del problema. El cuento trata la historia de Lobeiro, un individuo que atemorizaba a la comarca de Cebre. Los que se enfrentaban a su poder acababan destrozados, pero un día un grupo de aldeanos dinamita la casa del cacique causando su muerte y la de su familia. La historia, contada por un testigo de los hechos -el cura de Naya-, rebosa credibilidad y excelente oficio narrativo. Pardo penetra dentro de la estructura social de la comunidad rural para mostrarnos los atropellos y los crímenes espeluznantes de un personaje instalado como pieza fija en un sistema político del que recibe respaldo.

Por medio del terror, controla el municipio donde es dueño y señor, y como base fundamental que configura su propia existencia, es el representante del estado. El cacique no es otra cosa que una pantalla tras la cual se oculta todo un tinglado El cacique no es otra cosa que una pantalla tras la cual se oculta todo un tinglado
político, del cual sólo es uno de sus mecanismos, el más extraño de todo el político, del cual sólo es uno de sus mecanismos, el más extraño de todo
complicado y diverso engranaje que forma el poder. (Paredes Núnez, 1983: 99)

La voz de P.B. se inflama cuando por medio del cura de Naya clama contra el desamparo de los campesinos que sufren el azote de semejante intrigante. La condesa observa con viva preocupación un fenómeno que desprestigia al Poder central, porque el cacique triunfa donde la justicia está ausente: “Todo esto de leyes es nada más que conversación. Los magistrados, suponiendo que sean justificadísimos están lejos, y el cacique cerca" (Pardo Bazán, 1990:56, II).

La condesa, que fue siempre consciente de los defectos de España, utiliza la pluma para denunciar situaciones anómalas y para ofrecer propuestas de regeneración a una sociedad alicaída tras el desastre del 98. La respuesta de Pardo ante el descontento generalizado está en abrir la nación a Europa sin que esto suponga renegar de la tradición española. La escritora participa de este modo de la corriente crítica que denuncia las causas que llevaron a España al ocaso finisecular (Gómez-Ferrer, 1998:137). Como intelectual concienciada mira a Europa en busca de soluciones. Viaja a Bélgica para comprobar in situ cómo un país puede ser al mismo tiempo católico y moderno (Behiels, 2013: 139). Da conferencias en París donde hace gala de una elocuencia y de un exaltado patriotismo que no deja indiferente a la prensa internacional: "La frase de la Sra. Pardo Bazán es de fuego y de luz: laten en ella la fe y el más ardiente patriotismo" (Correspondence politique, 1899). Registra los males que sufre el Estado español, pero no desespera, sólo desea abrir los ojos de sus compatriotas... “Señala con sereno juicio las causas de nuestros males y desentraña con serena crítica lo que hay de bueno y de malo en nuestro carácter" (La Época, 1899). Como también subraya Joaquín Costa ${ }^{1}$ España se caracterizaba por ser el país del gobierno de los peores, pero si la clase dirigente era un despropósito, el pueblo -cuya pasividad enervaba a doña Emilia-, no era menos. La escritora lamentó siempre la estrechez de miras de una nación que "no se interesa más que por sucesos taurinos, intrigas electorales, dramas conyugales, crímenes, broncas..." (Gómez-Ferrer, 1998: 145). No obstante, reconoce que el divorcio entre los intereses del pueblo y los del Gobierno es total y así lo plasma en sus relatos, verdadera fuente para conocer su pensamiento: "Hoy únicamente estamos a quién gana las elecciones, a quién se hace árbitro de esta tierra... y todos los remedios son buenos, y caiga el que cayere" (Pardo Bazán, 1990:57, II). En efecto, Pardo se queja de una élite gobernante que sólo vive para ganar las elecciones y colocar a sus "paniaguados" (Gómez-Ferrer, 1998: 141). El cuento de referencia no es sólo un retrato del caciquismo en Galicia, sino que se erige como fiel reflejo de una clase política que le produce profunda desazón. Si en Viernes santo da cuenta del daño de un sistema político que se vale de hombres sin conciencia, en $\mathrm{El}$ indulto indaga en la desigualdad entre hombres y mujeres como origen del maltrato y de la violencia de género. La narradora constata con estupor cómo el tema de la mujer no interesa a nadie, y así lo denuncia reiteradamente desde las páginas de La Ilustración Artística: “La lenidad con esta clase de crímenes es grande. Sale bastante barato dar muerte a una mujer" (López Silva: 2012).

A través de sus escritos, obras de ficción y artículos en prensa, doña Emilia busca la regeneración de un país que desde el desastre del 98 queda reducido a la irrelevancia más absoluta. Sus aportaciones no estuvieron exentas de contradicciones y de partidismo ideológico, como cuando da una visión demasiado idílica del catolicismo belga (Behiels, 2013), tal vez para no malograr su ejemplo para España. Sin embargo, esto no disminuye ni un ápice su voluntad reformadora. Su presencia pública es la de la polemista ilustrada que analiza situaciones, denuncia irregularidades y ofrece propuestas de renovación. La ficción realista de la escritora gallega da perfecta cuenta de los problemas finiseculares de la España decimonónica, pues recrea con acierto una realidad que constituye la base de sus obras literarias.

\section{Conclusión}

Emilia Pardo Bazán hizo gala de una preocupación constante por los problemas políticos y sociales de España. Intelectual comprometida con su tiempo, muchos de los temas que conforman la base de sus narraciones proceden de la realidad convulsa que le tocó vivir. Hemos recogido dos relatos breves ๑El indulto y Viernes santo ๑para ilustrar

1 Joaquín Costa. Oligarquía y caciquismo. El autor señala que España no es una nación libre y soberana, pues lo único que existe son oligarquías. Expone una política de efectos provisionales pero inmediatos.

Rvista Internacional de Culturas y Literaturas, abril 2014 
hasta qué punto la escritora gallega era consciente del declive nacional, personificado en este caso en los crímenes domésticos y en el caciquismo.

La condesa poseía la agresividad y la inteligencia necesarias para denunciar a una sociedad que negaba a las mujeres el derecho a ser educadas en las mismas condiciones que el varón. Doña Emilia desafió las normas de la moral patriarcal exponiéndose al deterioro de su imagen pública. Sin embargo, nunca se amilanó y criticó con dureza la indiferencia de los poderes públicos ante lacras como la corrupción política, o lo que ella dio en llamar, mujericidio, en referencia al maltrato físico y al asesinato de mujeres.

Doña Emilia fue referencia obligada en revistas, periódicos y tertulias. Su polémica personalidad fue motivo de discusiones y descalificaciones de toda índole. Los colegas como Menéndez Pelayo achacan a frivolidad femenina su interés por los más variados asuntos.

En cuanto a doña Emilia, no hay que tomarla por lo serio en este punto ni en muchos otros. Tiene ingenio, cultura y sobre todo singulares condiciones de estilo; pero, como toda mujer, tiene una naturaleza receptiva y se enamora de todo lo que hace ruido, sin ton ni son y contradiciéndose cincuenta veces. Un día se encapricha de San Francisco y otro día de Zola. (Mayoral, 1990: 19)

Pero la condesa devolvió con creces todos los ataques de que fue objeto y respondió sobre todo con su talento. La problemática feminista fue tema constante a lo largo de su carrera. Doña Emilia intenta conciliar la carga ideológica de su conservadurismo social con la urgente necesidad de avances en la situación femenina. Al tiempo que retrata mujeres enérgicas, resueltas e independientes, (las soñadas mujeres del porvenir), no se olvida de la penuria de las mujeres humilladas. En El indulto narra un suceso verídico que golpea tanto su sensibilidad que no puede menos que dejar constancia del mismo: “La situación exactamente como la pinto se da en La Coruña. Pocas cosas he escrito con menos tranquilidad y aquel reposo que requiere el arte. La consideración de tan atroz suceso me tiene acongojada" (González Arias, 1997: 161). Este cuento nos brinda un retrato de mujer por quien la condesa siente ante todo piedad. Como se ha señalado, en el relato se recalca una de las ideas feministas de su autora: la solidaridad femenina, necesaria a su entender para vencer al opresor y hacer frente a la indiferencia de la sociedad.

Las interpretaciones que Pardo Bazán dio a los problemas de su época pueden ser discutibles y hasta contradictorias, pero no podemos negarle a doña Emilia la lucidez crítica de quien estuvo siempre a la altura de su tiempo. Mujer compleja, cristiana y sensual, tradicional y progresista, "fiel a su condición social e insegura acerca de ella" ${ }^{2}$, nunca cejó en su empeño reformador en un país que consideraba torpe y sin

2 Pedro Laín Entralgo en el Prólogo a La condición humana de Emilia Pardo Bazán de Delfín García Guerra, A Coruña, Xuntanza Editorial, 1990, p. 6 ideas de futuro. Su curiosidad intelectual nunca flaqueó; su sentido crítico, tampoco. Justo dos años antes de su muerte, firma un artículo revelador para La Nación de Buenos Aires en donde vuelve a insistir en la falta de seriedad y honradez de una clase política que define como corrupta y mediocre. Como si no bastase el ejemplo lapidario de Viernes santo, Pardo pone en su punto de mira a los políticos de provincias cuya máxima ambición es conseguir un acta de diputado de la que luego lucrarse: "Siempre hay varias carteras que se pueden repartir a unos y a otros, y para los cuales todos sirven" (Pardo Bazán, 1994: 254). Una vez que de diputado se llega a ministro los negocios afloran y el político se convierte en personaje: “El presupuesto, sobre todo en su sección de obras públicas, está ahí para que de su dorada pasta se corten trozos repartibles" (Pardo Bazán, 1994: 254). La escritora gallega lamenta que de la política irradie cuanto nos rodea, y que no haya cosa que no se le rinda. Escéptica respecto a parlamentarismo (García Guerra, 1990: 211), la condesa equipara la vulgaridad de los políticos españoles con la perenne atrofia de España, defecto que nunca se cansará de denunciar y de la que sus obras de ficción, personalizadas en este caso en los cuentos de referencia, son una prueba inapelable.

Emilia Pardo Bazán encarnó las inquietudes sociales y políticas del intelectual que se propone reflexionar sobre los problemas de su patria. Su feminismo combativo y su obsesión por la decadencia de España fueron dos de las batallas que libraría a lo largo de su vida. Los relatos objeto de estudio son un pequeño ejemplo de la innata curiosidad, talento y dotes de observación de la autora gallega. La variada temática de su cuentística es traslación directa de la realidad. Por sus historias desfila la actualidad de su tiempo, y en todas ellas queda constancia de la postura de la escritora ante los grandes desafíos de un periodo histórico que observó siempre en primera línea de fuego. Firme defensora del progreso y de la educación, creía que la ausencia de cultura conducía a la degradación moral. Mujer, aristócrata, pensadora, articulista, presidenta de la sociedad de Folclore gallego, catedrática de Lenguas Neolatinas, lectora y viajera incansable, Pardo es, sin duda alguna, un valor precioso de las letras españolas y una figura a reivindicar.

\section{REFERENCIAS BIBLIOGRÁFICAS}

Arnaud-Duc, N., “Las contradicciones del derecho”, Historia de las mujeres. El siglo XIX. Georges Duby-Michelle Perrot editores. Madrid, Taurus, 1993, pp. 91-127.

Behiels, L., "Claves belgas para la lectura de Por la Europa católica de Emilia Pardo Bazán", Revista de Literatura, 149, vol. LXXV, enero-junio (2013), pp. 139-162.

Costa, J., Oligarquía y caciquismo como la forma actual de gobierno en España: urgencia y modo de cambiarla. (2003). Internet. 03-05-2014, http://www.biblioteca.org.ar/libros/70931.pdf > 
Ciplijauskaité, B., La mujer insatisfecha. (El adulterio en la novela realista), Barcelona, Edhasa, 1984, $1^{\text {a }}$ edición.

García Guerra, D., La condición humana en Emilia Pardo Bazán, A Coruña, Xuntanza Editorial, 1990.

Gómez-Ferrer Morant, G., "Emilia Pardo Bazán en el ocaso del siglo XIX”. Cuadernos de Historia Contemporánea, 20 (1998), pp. 129-150.

González Arias, F., "La poética de Galicia en los cuentos de Emilia Pardo Bazán” en Estudios sobre Emilia Pardo Bazán. In Memoriam Maurice Hemingway. José M. González Herrán editor. Universidad de Santiago de Compostela, (1997), pp. 147-169.

González Martínez, P., Aporías de una mujer: Emilia Pardo Bazán, Madrid, Siglo XXI, 1988.

Kirpatrick, S., "La narrativa de la seducción en la novela española del siglo XIX” en Feminismo y teoría del discurso. Guilia Colaizzi editora, Madrid, Cátedra (1990) pp. 153-167.

López Silva, S., “La imagen de la mujer en la literatura española del siglo XIX: Emilia Pardo Bazán", Revista Esdrújula, 4 (2012), s.e. Internet. 13-04-2014 http://www.losfilologos.com/042012/06.La-imagen->

Mayoral, M., Edición a Los Pazos de Ulloa de Emilia Pardo Bazán, Madrid, Castalia, 1990.

Pardo Bazán, E., "La España de ayer y la de hoy”, Correspondence politique. Extractos de la prensa internacional. Conferencia en París (1899), pp.101-107. Proyecto Filosofía en español, 2010. Internet. 23-04-2014 http://www.filosofia.org./aut/001/1899epb7.htm>

—, "La conferencia de Doña Emilia Pardo Bazán", La Época, 22 de mayo de 1899, no 17.584, año LI, pp. 2-3 Proyecto Filosofía en español, 2010. Internet. 23-04-2014, http://www.filosofia. org/hem/189/e8990522.htm>

-, El indulto en Cuentos completos. José M. González Herrán editor, La Coruña, Fundación Barrié de la Maza, 1990, tomo I.

-, Viernes santo en Cuentos completos. José M. González Herrán editor, La Coruña, Fundación Barrié de la Maza, 1990, tomo II.

-, "Esbozo humorístico de un político de segunda categoría" en Crónicas en La Nación de Buenos Aires (1909-1921). Edición de Cyrus DeCoster, Madrid, Pliegos, 1994.

Paredes Núñez, J., La realidad gallega en los cuentos de Emilia Pardo Bazán. A Coruña, Ediciós do Castro, 1983.

Peñas Ruiz, A., “Emilia Pardo Bazán: Cartografías en torno a la mujer”, La Tribuna-Cadernos de Estudos da Casa Museo de Emilia Pardo Bazán, s.e. Internet. 13-04-2014 http://www.academia. edu/Emilia Pardo Bazán 